\title{
Perspectives of development of X-ray analysis for material composition
}

\author{
I.F.Mikhailov, A.A.Baturin, A.I.Mikhailov, L.P.Fomina \\ National Technical University "Kharkiv Polytechnical Institute", \\ 21 Frunze Str., 61002 Kharkiv, Ukraine
}

Received November 3, 2015

\begin{abstract}
Perspectives are considered for increasing the sensitivity of X-ray analysis and broadening the range of measurements toward chemical elements with small atomic numbers up to hydrogen at the expense of formation of the optimized selective spectrum from a preliminary beam for exciting fluorescence and observing scattering peaks and diffraction reflections. It has been shown that low-power preliminary sources (X-ray tube, $20 \mathrm{~W}$ ) are able to provide the detection limit for trace impurities near $0.1 \mathrm{ppm}$, and for hydrogen in metals - up to $10 \mathrm{ppm}$. The data presented are hopeful for attaining X-ray analysis sensitivity at the level of ppb units due to application of powerful preliminary beams (synchrotron, undulators, wigglers, etc.).
\end{abstract}

Keywords: X-ray analysis, Compton scattering, X-ray spectrometers.

Рассмотрены перспективы повышения чувствительности рентгеновского анализа и расширения диапазона измерений в область химических элементов с малыми атомными номерами, вплоть до водорода, путем формирования из первичного спектра источника селективного спектра для возбуждения флуоресценции и наблюдения пиков рассеяния и дифракционных отражений. Показано, что первичные источники малой мощности (рентгеновская трубка 20 Вт) могут обеспечивать предел обнаружения следовых примесей на уровне $0,1 \mathrm{ppm}$. Использование мощных пучков первичного рентгеновского излучения (СИ, ондуляторов, вигглеров и т.д.) позволит довести чувствительность анализа до единиц ppb при сохранении всех преимуществ рентгеновских методов.

Перспективи розвитку рентгенівського аналізу складу матеріалів. І.Ф.Михайлов, А.О.Батурин, А.І.Михайлов, Л.П.Фолина.

Розглянуто перспективи підвищення чутливості рентгенівського аналізу та розширення діапазону вимірювань в область хімічних елементів з малими атомними номерами шляхом формування з первинного спектра джерела селективного спектру для збудження флуоресценції, а також спостереження піків розсіювання та дифракційних віддзеркалень. Показано, що первинні джерела малої потужності (рентгенівська трубка 20 Вт) можуть забезпечувати межу виявлення слідових домішок на рівні 0,1 ppm. Використання потужних пучків первинного рентгенівського випромінювання (СВ, ондуляторів, вігглерів та інше) дозволить довести чутливість аналізу до одиниць ррb при збереженні всіх переваг рентгенівських методів.

\section{Introduction}

X-ray methods for analysis of materials composition are widely applied due to high precision, rapidness, and simplicity of sample preparation. Nevertheless, these have been used rather limitedly for solution of modern analytical problems, for example, in the area of nanotechnologies, because of comparably low sensitivity. A characteristic value of an impurity detection limit for standard X-ray optic scheme is $5 \div 30 \mathrm{ppm}$, while solution of the most modern analytical tasks requires the measurement sensitiv- 
ity about 0.1-10 ppm. Additionally, quite limited is the possibility of revealing chemical elements with atomic number $Z_{a}<6$.

The aim of the present work is increasing sensitivity and broadening the measurement range into the area of chemical elements with low atomic numbers at the expense of formation, from the source preliminary spectrum, an optimized selective spectrum for excitation of fluorescence and observation of scattering peaks and diffraction reflections.

We propose a complex approach, at which there is formed a united X-ray spectrum containing fluorescence lines, diffraction reflections, as well as lines of Compton and Rayleigh scattering. By the fluorescence lines, X-ray fluorescent analysis (XFA) is carried out; by the ratio of Compton and Rayleigh scattering peaks, impurities with $Z_{a}<6$ are measured; and diffraction reflections are used for structure attestation of multi-phase samples.

\section{Top possibilities of $X$-ray fluorescent analysis}

In XRF, excitation of impurity fluorescence is realized by a broad-band spectrum of an X-ray tube. Usually, the feeding voltage is set by a factor $1.5 \div 2$ higher than energy absorption edge for a series of analyzed elements lines [1]. This exceeding guaranties that the area of the preliminary spectrum high intensity will be positioned directly behind the absorption edge for this series, thus providing maximum possible contrast of analytical lines. The continuous spectrum long-wavelength range which is positioned lower the spectrum absorption edge, is scattered at the sample and becomes a source of background directly in the spectrum range where characteristic lines of studied impurities are positioned. The short-wavelength range exciting the fluorescence of the sample chemical elements is also scattered at the sample and creates parasite charging the detector. Modern solid-state detectors based on silicon have limited speed of counting and work sufficiently in the energy range $1 \div 30 \mathrm{keV}$ under charging not more $10^{4}$ counts/s. Therefore, any scattering background charging the detector results in necessity to decrease the tube current that decreases impurities intensity of fluorescence and gets worse the analysis sensitivity.

In Fig. 1 the dependence of trace impurities detection limit on atomic number is shown. This dependence was calculated

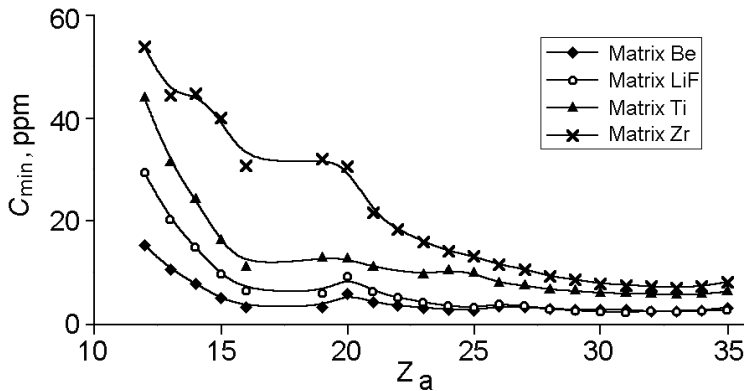

Fig. 1. Dependences of detection limit on impurity atomic number. Theoretical calculation for a standard XRF scheme.

theoretically for standard XRF scheme (excitation of impurity fluorescence by radiation of an X-ray tube with silver anode) for analysis of the samples with different matrix. The detection limit was calculated for a series from six elements (by increasing atomic numbers), the voltage at the tube was chosen in order this would be twice as higher than the absorption edge of the most heavy element in the series, i.e. with the highest atomic number. The tube current for each variation of feeding voltage was chosen in order that the detector charging would not exceed $10^{4}$ counts/s. Obviously, the heavier is the matrix, the more will be absorption of fluorescent radiation and, respectively, the analysis sensitivity gets worse (the detection limit increases). There is inverse dependence on atomic number of impurity: the more is impurity atomic number, the better fluorescent radiation passes through the matrix material, and the detection limit decreases. The presented theoretical results show that under broad-band excitation in the standard XRF scheme, because of high intensity of scattering background, it is difficult to achieve analysis sensitivity at the level of $10 \mathrm{ppm}$. In order to increase the sensitivity it is necessary to form the spectrum from the preliminary spectrum of the X-ray tube that would provide high efficiency of fluorescence excitation at minimum level of the scattering background.

We put the general task: what spectrum would be necessary formed from the spectrum of the preliminary source to achieve maximum sensitivity for measurement of desired impurity in the given matrix. It is clear a priori, that this spectrum would contain a series of monochromatic lines positioned in the given ranges of the spectrum at minimum level of continuous spectrum background. 


\section{Unit of preliminary spectrum formation}

In order to solve this task, we added the unit of the preliminary spectrum formation (UPSF) to the standard XRF scheme (see Fig. 2). This unit forms the spectrum including a series of monochromatic lines positioned in given wavelength ranges for effective exciting fluorescence and preventing detector charging by parasite signal. Additionally, the UPSF provides minimal scattering background. Technical solutions in the UPSF may be different, but these are based on three main ways for excitation of fluorescence in the sample [1-3]. We do not consider the schemes for fluorescence selective excitation by polarized radiation and by grazing beam at Bruster angle of total external reflection, because these schemes exclude getting the continuous spectrum onto the sample. In the first case, the long-wavelength part of the preliminary spectrum is removing by a filter, and the short-wavelength (the "bell" of bremsstrallung radiation) - by increasing the tube voltage (more than $100 \mathrm{kV}$ ) - is transferred beyond the energy range of preliminary beam effective scattering by polarizer atoms [4]. In the second case, - due to small incident angle (less than $1^{\circ}$ ) - the preliminary radiation penetrates into the sample bulk at deep not exceeding $10 \mathrm{~nm}$, thus the influence of the substrate is excluded, so, the scattering is concentrated in the specular component which is cut off by collimators, and is practically absent in the fluorescence spectrum [5]. The higher contrast of the analytical spectrum is required for solution of a concrete analytical problem, the more energy is to be removed from the spectrum of an X-ray tube. By the order of luminous power decreasing and increasing the spectrum contrast, there are following known schemes of fluorescence excitation using: (1) preliminary spectrum of X-ray tube with filtration [1]; (2) quasi-monochromatic spectrum of a secondary target fluorescent radiation $[1,6]$; (3) X-ray tube preliminary spectrum monochromatized by reflection from a single-crystal face [1-3, 7].

By increasing the filter thickness, it is possible to cut off totally the low-energy range of the bremsstrallung spectrum, but the high-energy range will still get into the detector, thus forcing tube current to belowerd. Therefore, for the scheme with filtration, the detection limit is not better than 1-10 ppm that does not satisfy the

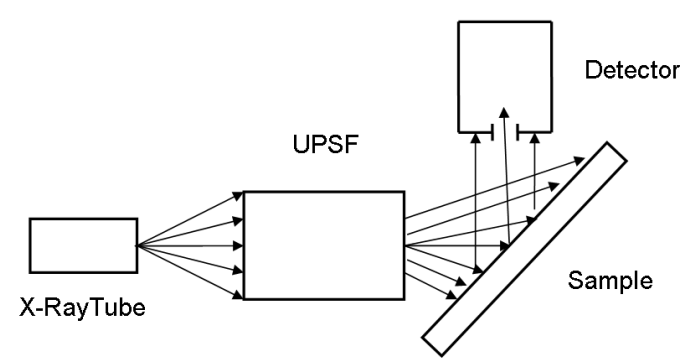

Fig. 2. X-ray optic scheme with a unit of the preliminary spectrum formation (UPSF).

requirements mentioned in Introduction. Monochromatization drastically lowers both the parasite signal and the scattering background, but allows achieving desired detection limit $\left(C_{\text {min }} \leq 1 \mathrm{ppm}\right)$ only for narrow range of chemical elements [6], because the efficiency of fluorescence excitation drops drastically with distancing the exciting line from the impurity absorption jump. That is, if it is required to measure the contain of several impurities with significantly different atomic numbers $\left(\Delta Z_{a}>8\right)$, it is necessary - in the incident spectrum - to have a set of characteristic lines positioned near absorption edges of the elements measured at minimum broad-band background. The best spectrum contrast and minimum detection limit are provided by optimization of the UPSF parameters, namely, feeding voltage, parameters of filter and target, and geometry of the scheme.

\section{Optimization of UPSF parameters by criterion of detection limit}

The criterion of the optimization is the known expression for detection limit of an impurity line in the spectrum. This expression connects background characteristics $N_{b}$ in the position of an impurity characteristic line with concentration sensitivity $\partial N_{i} / \partial C$, i.e. variation of the signal per a unit of concentration variation [7]

$$
C_{\min }=3 \frac{\sqrt{N_{b i}}}{\partial N_{i} / \partial C} .
$$

The optimization is carried out theoretically from the condition of zero total differential of the detection limit $C_{m i n}$ :

$$
d C_{\min }(U, \tau, \mu, \sigma, t, \varphi, \psi)=0,
$$

where $U$ is feeding voltage; filter and target parameters: mass coefficients of absorption 
$\tau$, attenuation $\mu$, and scattering $\sigma$; thickness $t$; scheme parameters and geometry $(\varphi-$ incident angle, and $\psi-$ exit angle). For solution of the problem, three fluxes of Xray radiation are under consideration. $\Phi_{01}(\lambda)$ - the flux of the preliminary radiation (spectrum); $\Phi_{02}(\lambda)$ - the flux of radiation which is formed by the scheme of fluorescence excitation (formation unit UPSF); $\Phi_{03}(\lambda)$ - the radiation flux recorded by detector. The flux of the X-ray tube $\Phi_{01}(\lambda)$ includes characteristic radiation of the anode material $\Phi_{c h}(\lambda)$ and bremsstrallung radiation $\Phi_{c o n}(\lambda)$ :

$$
\Phi_{01}(\lambda)=\Phi_{c o n}(\lambda)+\sum_{i} \delta\left(\lambda-\lambda_{i}\right) \Phi_{c h}(\lambda),
$$

where $\delta\left(\lambda-\lambda_{i}\right)$ is delta-function.

The flux $\Phi_{02}(\lambda)$ is determined by UPSF, and this will be discussed below in detail. The flux $\Phi_{03}(\lambda)$ determining the detection limit $C_{m i n}(\lambda)$ for $i$-th element emitting fluorescent radiation with wavelength $\lambda_{i}$, similarly to $[7,8]$ may be expressed as:

$$
\begin{gathered}
\Phi_{03}(\lambda)=\frac{S_{s} \sin \varphi}{4 \pi r^{2}} \cdot \frac{\Phi_{02}(\lambda) \sigma_{3}(\lambda)}{\mu_{3}(\lambda)\left(\frac{1}{\sin \varphi}+\frac{1}{\sin \varphi}\right)}+ \\
+\frac{S_{s} \sin \varphi}{4 \pi r^{2}} \cdot \sum_{i=1}^{n} \frac{1}{1+\frac{\left(\lambda_{i}-\lambda\right)^{2}}{\left(\Delta \lambda_{i} / 2\right)^{2}} \frac{1}{\Delta \lambda_{i}} C_{i} \times} \\
\times \frac{p_{i} \omega_{q i}}{\sin \varphi\left(1-\frac{1}{S_{q i}}\right) \int_{\lambda_{\text {edge }}}^{\lambda_{q i}} \frac{\Phi_{02}(\lambda) \tau_{i}(\lambda)}{\sin \varphi}+\frac{\mu_{3}\left(\lambda_{i}\right)}{\sin \psi}} d \lambda,
\end{gathered}
$$

where $S_{s}$ is the irradiated sample part "observable" by the detector; $r$ is distance from the sample to the detector; $\lambda_{\text {edge }}$ is wavelength of the continuous spectrum edge; $\lambda_{q i}$ is wavelength of absorption jump for $i$-th element of the sample; $\Delta \lambda$ is half-width of the spectrum line (resolution of the spectrometer); $\sigma_{3}(\lambda)$ and $\mu_{3}(\lambda)$ are mass coefficients of scattering and attenuation of the flux $\Phi_{02}$ by atoms of a chemical element; $\tau_{i}(\lambda)$ is absorption mass coefficient of $\Phi_{02}$ flux by the atoms of the chemical element analyzed; $\mu_{3}\left(\lambda_{i}\right)$ is mass coefficient of attenuation of fluorescent radiation of the analyzed chemical element by the sample material; $p_{i}$ is relative intensity of the line in the series; $C_{i}, \omega_{q i}, S_{q i}$ are, respectively, concentration, fluorescence yield and the value of absorption jump for $i$-th element.

The first term in the (3) describes the scattering function of the flux $\Phi_{02}$ and determines the main constituent of the background. The second term describes analytical lines of the sample chemical elements, then, the detection limit is determined according to the formula (1):

$$
C_{\min }(\lambda)=\frac{3 \sqrt{\sin \varphi}}{C_{i} p_{i} \omega_{q i} \sqrt{\frac{S}{4 \pi r^{2}}}} \times
$$

$$
\times \frac{\left(\frac{\Phi_{02}(\lambda) \sigma_{3}(\lambda)}{\mu_{3}(\lambda)\left(\frac{1}{\sin \varphi}+\frac{1}{\sin \psi}\right)}\right)^{1 / 2}}{\sum_{i=1}^{n} \frac{1}{1+\frac{\left(\lambda_{i}-\lambda\right)^{2}}{\left(\Delta \lambda_{i} / 2\right)^{2}}} \frac{1}{\Delta \lambda_{i}} \int_{\lambda_{\text {edge }}}^{\lambda_{3}} \frac{\Phi_{02}(\lambda) \tau_{i}(\lambda)}{\sin \varphi}+\frac{\mu_{3}\left(\lambda_{i}\right)}{\sin \psi} d \lambda} .
$$

The formula (4) is general and can be applied for any function of the preliminary spectrum, for example, for radiation of X-ray tube and synchrotron. On the base of this expression we can consider in general the problem of optimization for UPSF parameters in accordance with Eq. (2).

\section{Practical search for parameters of the scheme}

Characteristic radiation flux intensity $I_{c h}$ of anode material is determined by the characteristic line quantity of photons emitted per a second in the solid angle 1 steradian. Bremsstrahlung radiation or continuous spectrum is determined by spectral density $\partial I_{c o n} / \partial \lambda$ - the quantity of photons within a unit energy range, emitted per a second in the solid angle 1 steradian. The values $I_{c h}$ and $\partial I_{c o n} / \partial \lambda$ set the shape of characteristic and continuous spectra of an $\mathrm{X}$-ray tube and are determined by formulas from [8]:

$$
\begin{gathered}
I_{c h}=5 \cdot 10^{14} i_{a} \frac{\gamma \omega_{q} p R}{Z_{a}}\left(\frac{\lambda 1 q}{\lambda_{\text {edge }}}-1\right)^{1.67}\left[\frac{\text { photon }}{\mathrm{sster}}\right],(5) \\
I_{\text {con }}=-1090 \cdot 10^{8} Z_{a} i_{a} \frac{1}{\lambda^{2}}\left(\frac{\lambda}{\lambda_{\text {edge }}}-1\right)\left[\frac{\text { photon }}{\mathrm{s} \mathrm{sternm}}\right],(6
\end{gathered}
$$




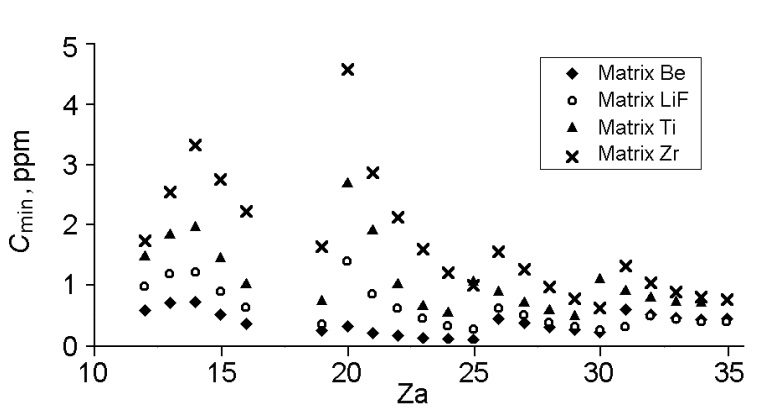

Fig. 3. Detection limits depending on the impurity atomic number. Calculated theoretically for optimized scheme with a secondary target.

where $R=\left(1-\frac{7 Z_{a}-80}{14 Z_{a}-80}\right), \quad Z_{a}$ is atomic number of anode material; $i_{a}$ is anode current; $\gamma=3.8 \cdot 10^{-2}$ for $K$-series and 0.11 for $L$-series; $\omega_{q}$ is fluorescence yield; $p$ is the portion of intensity of the line in the spectral series; $\lambda_{1 q}$ is wavelength of absorption jump for X-ray tube anode material; $\lambda_{\text {edge }}=$ $12.39 / U(\mathrm{kV})$ is the wavelength of the continuous spectrum edge.

Thus, the UPSF may be considered as the operator of action onto the spectrum of the preliminary radiation source. The radiation flux incident onto the sample can be obtained from the expression for the preliminary radiation flux of the $\mathrm{X}$-ray tube (Eqs. 5 and 6 ) by action of the following operators:

filtration

$$
\exp \left(-\mu_{f}(\lambda) t_{f} \rho_{f}\right)
$$

scattering

$$
\frac{\sigma_{2}(\lambda)}{\mu_{2}(\lambda)\left(\frac{1}{\sin \varphi}+\frac{1}{\sin \psi}\right)}
$$

fluorescence

$$
\int_{\text {edge }}^{\lambda 2 q} \frac{\tau_{2}(\lambda)}{\frac{\mu_{2}(\lambda)}{\sin \varphi}+\frac{\mu_{2}\left(\lambda_{2}\right)}{\sin \psi}} d \lambda,
$$

and monochromatization

$$
k \frac{\left(1+\cos ^{2} 2 \theta\right) \lambda^{3}}{\sin 2 \theta \mu(\lambda)}
$$

where $\mu_{f}(\lambda), t_{f}$ and $\rho_{f}$ are filter parameters (mass coefficient of attenuation of the preliminary spectrum, thickness, and density,

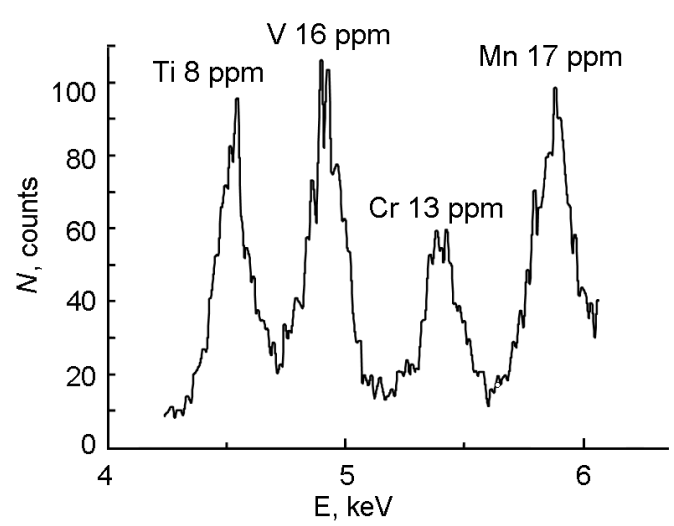

Fig. 4. A fragment of spectrum for aluminum SS 1 (GSZ AP-434(k)-02). Secondary radiator - germanium. Time of the spectrum accumulation is $300 \mathrm{~s}$.

respectively); $\sigma_{2}(\lambda), \mu_{2}(\lambda), \tau_{2}(\lambda), \mu_{2}(\lambda)$ are parameters of the secondary target (respectively, mass coefficients of scattering, attenuation, and absorption of the preliminary radiation by the target material, and mass coefficient of attenuation of target atoms fluorescence by its material); $\lambda_{2 q}$ is wavelength of absorption jump for target material.

In Fig. 3 the dependence of the detection limit on atomic numbers for trace impurities is shown. This dependence was calculated theoretically for XRF scheme equipped by UPSF with optimized parameters. The detection limit, as in the case of a standard XRF scheme (see Fig. 1) was calculated for a series consisting of six elements. Material of the secondary radiator was chosen so that its atomic numbers being two number higher than the atomic number of the heaviest element of the series. Therefore, in Fig. 3 we observe decreasing the detection limit with increasing atomic number within each series. Growing the sensitivity is due to increasing the efficiency of fluorescence excitation as the secondary target characteristic line is approaching to absorption edge of the impurity analyzed. Voltage at the tube with silver anode is $35 \mathrm{kV}$. Tube current was chosen so as detector charging does not exceed $10^{4}$ counts/s.

The detection limit is lowered by an order of value in comparison with the standard XRF scheme (see Fig. 1) that opens perspectives for analysis of pure materials. In Fig. 4, a fragment of the spectrum is shown for the standard sample SS1 of pure aluminum, containing the lines $\mathrm{Ti}-\mathrm{K}_{\alpha}, \mathrm{V}-\mathrm{K}_{\alpha}, \mathrm{Cr}-\mathrm{K}_{\alpha}$ and $\mathrm{Mn}-\mathrm{K}_{\alpha}$. The contrast of analytical lines is so high that pro- 
vides detection limits for these elements from 1 to $2 \mathrm{ppm}$ even at small time of counts accumulation $300 \mathrm{~s}$. These values are, at least, by an order of value higher than in the standard XRF scheme. Due to high contrast, the sensitivity can be increased up to $0.1 \div 0.3$ ppm by increasing the exposure time to $1 \mathrm{~h}$. Such sensitivity is quite enough for practical application for solution of many modern analytical tasks.

Let us consider once more analytical problem, namely, analysis of iodine content in human's organism (concentration range $0.05 \div 0.2 \mathrm{ppm}$ ), which is necessary for diagnostics and correction of cure of some human heavy illnesses [9]. Presently, such analyses are quite complex and carried out using expensive equipment during several days. The X-ray technique is very promissory for such measurements and significantly less expansive, because only one hour is required for measurements. Excitation of $\mathrm{X}$-ray spectra is realized by radiation of the $\mathrm{Cr}$ secondary target. The line $\mathrm{Cr}-\mathrm{K}_{\alpha}$ of this radiator, after scattering on the sample, is attenuated by vanadium filter positioned before SSD detector.

In Fig. 5 substantial growing of $J-L_{\alpha}$ and $J-L_{\beta}$ lines intensities is observed with increasing iodine content in the sample as a result of addition of calibration admixtures. Also, independent determination of iodine content by $J-L_{\alpha}$ and $J-L_{\beta}$ lines is possible. Concentration sensitivity by $L_{\alpha}$ is 20 counts $/ 100 \mu \mathrm{g}$ and by $L_{\beta}-13$ counts $/ 100 \mu \mathrm{g}$, background intensity $N_{b}$, is, respectively, 140 and 160 counts.

During substitution in Eq. (1) for detection limit, it should be taken into account that $N_{b}$ value is determined by averaging over fourteenth channels, while peak intensity - by adjustment of the line profile with half-width of fourteenth channels. Therefore, count accumulation at the background is $N_{b}=140 \cdot 14$, and for determination of concentration sensitivity $-\partial N / \partial C=20 \cdot 14$. So, it follows, that under measuring by $L_{\alpha}$ the detection limit is $47.4 \mu \mathrm{g} / \mathrm{dm}^{3}(0.047 \mathrm{ppm})$, and by $L_{\beta}$, respectively, $-780 \mu \mathrm{g} / \mathrm{dm}^{3}(0.078 \mathrm{ppm})$. This result obtained using the low-power X-ray tube, surpasses by sensitivity the achievements of XRF analyses with application of modern synchrotron sources [10].

Thus, transition from the scheme of fluorescence broad-band excitation in the standard XRF to the scheme of selective excitation using the unit of formation (UPSF)

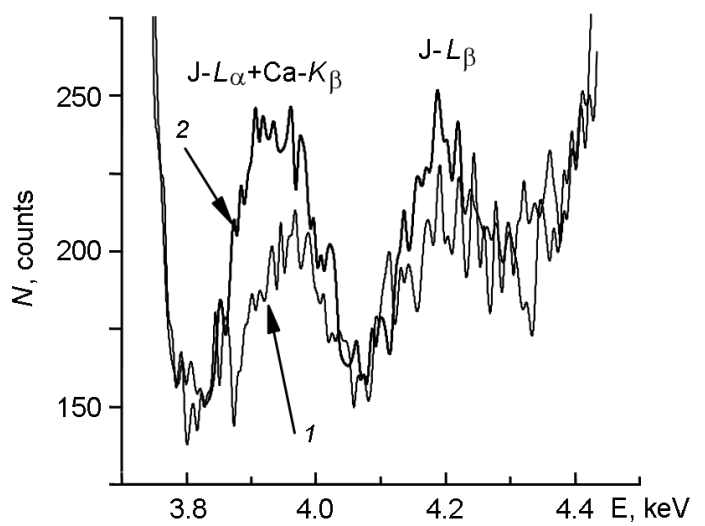

Fig. 5. Fragments of spectra for samples with different iodine content: 1 - initial; 2 with addition of $300 \mu \mathrm{g} / \mathrm{dm}^{3}$ iodine.

with optimized parameters allows sensitivity increasing by $1 \div 2$ orders of value.

\section{Structure certification of multi-phase systems}

For studying the sample structure and chemical composition, usually, two alternative X-ray schemes are applied for measurements: structure analysis is performed under conditions of small angle divergence $\left(\Delta 2 \theta \approx 0.1 \div 0.5^{\circ}\right)$, while X-ray fluorescent - under maximum one $\left(\Delta 2 \theta \approx 8 \div 60^{\circ}\right)$. In spite of principle differences between the schemes, fluorescence spectra always contain the scattered by the sample spectral lines of exciting radiation (scattering peaks). Without special adjustment these lines are hindering factors in the X-ray spectral analysis, because their intensity depends on getting one or another phase into Bragg-reflection conditions [11]. Under noncertified preliminary X-ray radiation and collimation system of the spectrometer, application of data on the intensity of these reflections for quantitative calculations is rather difficult and may result in errors in measurements. Nevertheless, combination of the X-ray "structure" scheme and X-ray "spectral" one in the same instrument would allow solution a lot of applied problems. A visual example of application of this method is analysis of steel composition, where determination of light element concentrations: silicon, phosphor, and sulfur, as well as all alloying elements is carried out by intensity of fluorescence lines, while analysis of carbon content (being non-effective by fluorescence lines) can be performed by diffraction (structure) reflections of cementite $\mathrm{Fe}_{3} \mathrm{C}$ [12]. 


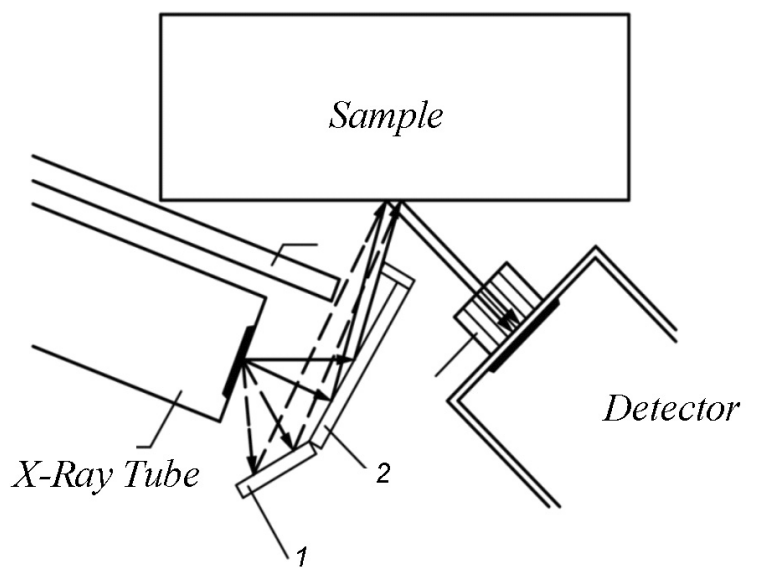

Fig. 6. UPSF arrangement for analysis of low-alloyed steels. 1 - single crystal $\mathrm{KCl}$, secondary target $\mathrm{Sc} / \mathrm{Nb}$.

The scheme of UPSF for analysis of steels is shown in Fig. 6. The unit is equipped by a $\mathrm{KCl}(001)$ crystal-monochromator (1) tuned on the refection of the silver anode $L$-line for exciting fluorescence of light elements with atomic numbers from 12 to 17 , and a double-layer scandium/niobium secondary radiator (2). Small distance between the sample and the detector (less than $6 \mathrm{~mm}$ ) allows lowering absorption in air for light element radiation up to magnesium $\left(Z_{a}=12\right)$ and to perform analysis of these impurities without vacuuming.

Steel casting without special treatment may be considered according to a quasi-binary diagram of state: iron $(\alpha-\mathrm{Fe})-$ cementite $\left(\mathrm{Fe}_{3} \mathrm{C}\right)$ as a two-phase system. $\alpha$-Fe does not contain carbon, practically; therefore, the carbon content in the steel is reasonably to connect with the content of a carbon-containing phase - cementite, which crystalline lattice, by stoichiometry, contains $6.67 \%$ mass of this chemical element. In other words, 1 mass \% carbon concentration in the steel corresponds to $15.0 \%$ content of $\mathrm{Fe}_{3} \mathrm{C}$.

Let us consider quantitative $\mathrm{X}$-ray phase analysis of cementite in steel by the combined spectrum of X-ray fluorescence and diffraction. In order to obtain such combined spectrum, the UPSF is equipped by secondary radiators made from the materials which are absent in the sample composition. For steel, it is, for example, scandium, potassium, and chlorine. Characteristic lines of such secondary targets pass through the collimation system and reflect from sample crystallographic planes according to WolfBragg relation $\lambda=2 d \cdot \sin \theta$. Let the collima-

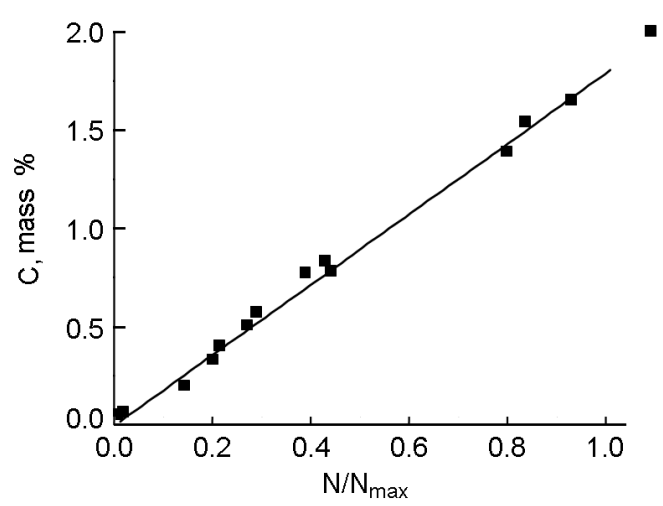

Fig. 7. Calibration function for measurement of carbon in low-alloyed steels by diffraction reflections of cementite.

tion system be adjusted for a special angle range $\theta \pm \Delta \theta$, to which the determined range $d \pm \Delta d$ corresponds. If in this $d$ range the lattice of the studied phase has the reflecting planes, characteristic line of the radiator in the spectrum would be strengthened by the Bragg reflection from the sample.

The collimation system is adjusted for transmitting the range of scattering angles where there are only cementite reflections, and no $\alpha$-Fe reflections. In Fig. 7, the calibration function on carbon is shown which was constructed by scattering integral intensity in the range $d=1.89 \div 1.69 \AA$.

In this range there are no $\alpha$-Fe reflections, but there are strong lines of $\mathrm{Fe}_{3} \mathrm{C}$ : $d=1.867 \AA$ and $d=1.687 \AA$. Low background in the scheme with the complex reradiator allowed obtaining very high sensitivity of calibration $\geq 64.4 \%$ of intensity variation per $1 \%$ mass variation of carbon concentration. Thus, at real precision of the integral intensity measurements about $0.5 \%$, the precision of carbon measurements 0.01 mass $\%$ is principally provided.

Achieved experimentally value $S=$ 0.047 mass \% of square-root deviation of the calibration function by three different series of standard samples (series 127, 154, and UG) provides the precision of carbon measurements $0.03 \div 0.05$ mass $\%$ in the concentration range from 0.02 to $1.4 \%$ mass that is quite acceptable for practical measurements.

In Fig. 8, a fragment of a carbon steel $\mathrm{X}$-Ray spectrum containing both fluorescence lines of the components and diffraction reflections of the sample. There are observable the lines of light elements: silicon, phosphor, and sulfur with concentrations $\sim 0.01-0.1$ mass $\%$. Obviously, it is 


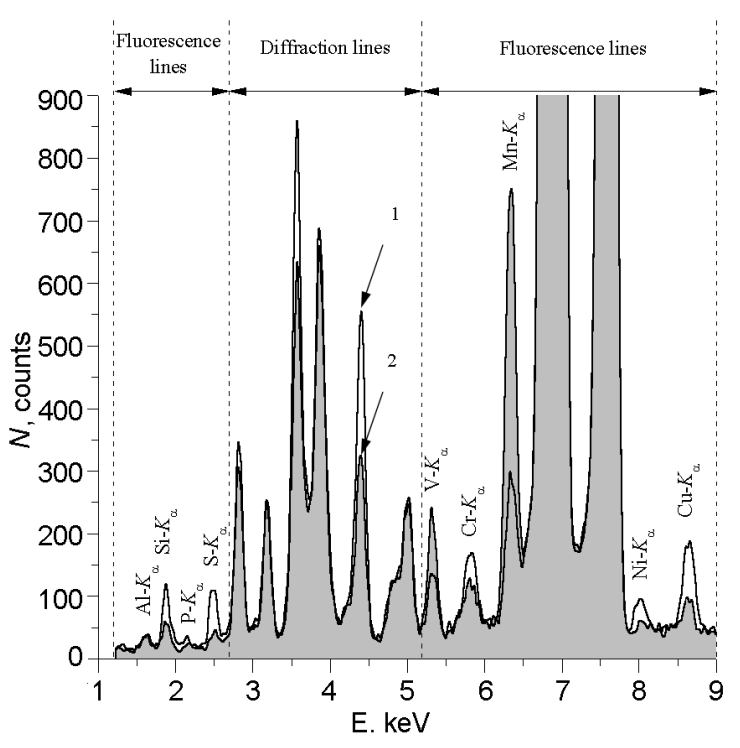

Fig. 8. Fragments of X-ray spectra for carbon steels with carbon contents 0.053 mass \% (curve 1) and 0.43 mass \% (curve 2). The $\mathrm{X}$-ray tube is of shooting-through type with silver anode. $U=35 \mathrm{kV}, I=250 \mu \mathrm{A}$. Crystall-monochromator is $\mathrm{KCl}(002)$, $\mathrm{Sc} / \mathrm{Nb}$ double-layer secondary target. Exposure $120 \mathrm{~s}$.

possible to measure intensities of fluorescent lines for light elements and structure diffraction reflections within a united spectrum.

It is worth to note, that possibilities of the method are not limited by analysis of low-alloyed steels. The secondary radiators and the collimation system can be adjusted for the main diffraction reflections of other phases of interest that would allow quantitative phase analysis simultaneously with $\mathrm{X}$-ray fluorescent analysis of similar materials: mineral ores and other multi-phase systems.

\section{Determination of first elements of Periodical Table by the ratio of Compton-to-Rayleigh scattering intensities}

Low background provided by UPSF allows carrying out the measurements of the Compton-to-Rayleigh scattering intensity ratio. In the classic Compton's work [13], 1923, there was revealed a strong dependence of the ratio of Compton and Rayleigh peaks on the atomic number of the scattering material. Compton pointed out onto the possibility to study light elements by this ratio, but mentioned difficulties caused by non-controlled superposition of Bragg reflections onto the Rayleigh peak under

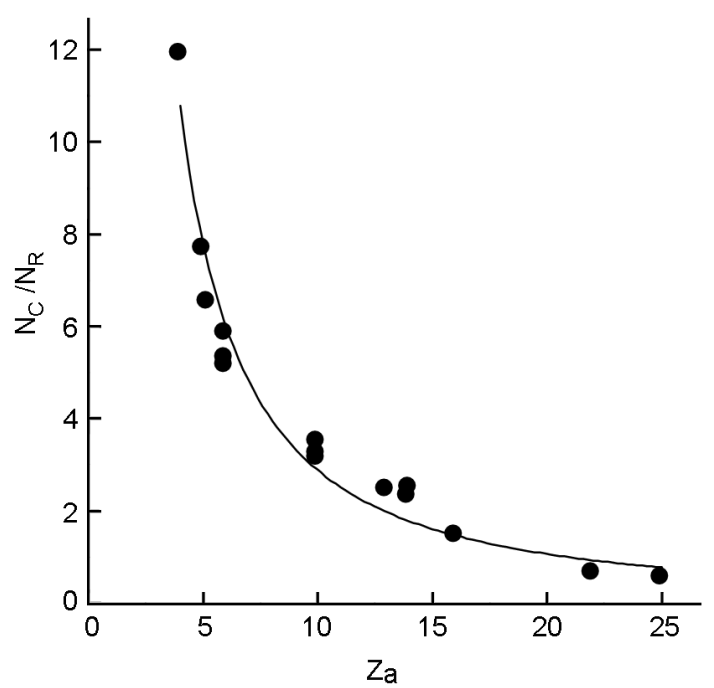

Fig. 9. Dependence of Compton-to-Rayleigh peak intensity ratio on atomic number of the sample material.

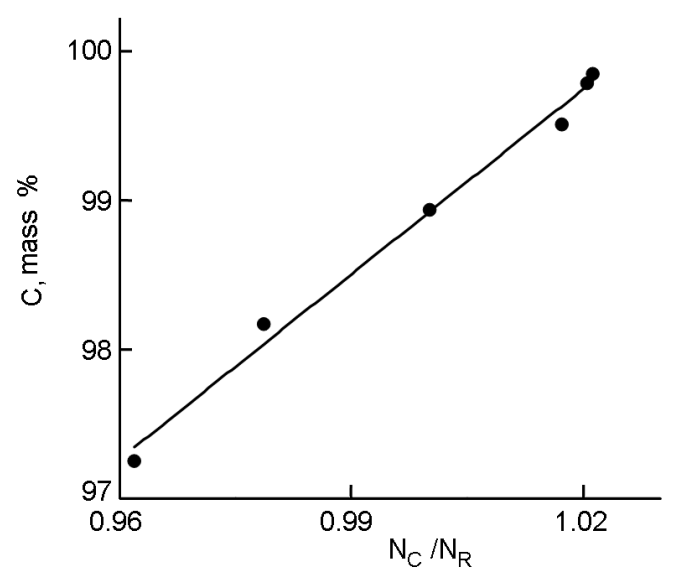

Fig. 10. Dependence of Compton-to-Rayleigh peak intensity ratio on the main component content in CO1-CO6 standard samples of pure aluminum.

studying crystalline materials. This difficulty can be overcome successfully by choice of the probing radiation and the scattering angle [14].

In Fig. 9, our experimental plot is shown for illustration of a unique possibility to measure concentrations of first elements of the Periodic Table. Investigations have shown that the lower is the atomic number of the impurity the higher is the sensitivity of its determination. This method is rather effective for revealing heavy impurities in a light matrix, or light impurities in a heavy matrix. Although the method gives the integral evaluation of all the impurities without specification of their types, it is very con- 


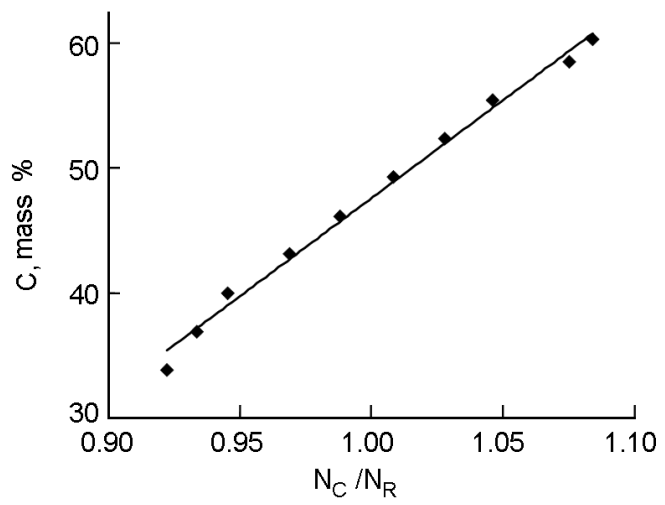

Fig. 11. Calibration function of $\mathrm{Al}_{2} \mathrm{O}_{3}$ content in powder $\mathrm{Al}-\mathrm{Al}_{2} \mathrm{O}_{3}$ mixtures by the ratio of Compton-to-Rayleigh peak intensities. The secondary radiator is molybdenum. Exposure $120 \mathrm{~s}$.

venient for the rapid assessment of the material purity.

At the calibration plot (Fig. 10) for standard samples of preliminary aluminum (light matrix), a linear dependence of Compton-to Rayleigh peak intensity ratio, $N_{C} / N_{R}$, on aluminum content is observable in the range mass portions $97.3 \div 99.9 \%$ mass. Using this dependence, it is possible to reject the preliminary aluminum avoiding laborious work on determination of all impurity concentrations. Indeed, at relative concentration sensitivity $\frac{1}{N} \cdot \frac{\partial N}{\partial C}$ (Fig. 10) and precision of measuring the intensity ratio $N_{C} / N_{R}$ about $0.1 \%$, it is possible to determine the aluminum purity up to $99.95 \%$ mass.

It should be noted that quantitative analysis of element content with $Z \leq 8$ in heterogenic samples is rather difficult because of high dispersion of the calibration function which is difficult to control experimentally. So, for example, the calibration of powder $\mathrm{Al}-\mathrm{Al}_{2} \mathrm{O}_{3}$ mixtures by oxygen in the range of $\mathrm{Al}_{2} \mathrm{O}_{3}$ mass portions from 34 to 61 mass $\%$ is characterized by dispersion 3.22 mass \%, that causes low precision of measurements by the $\mathrm{O}-\mathrm{K}_{\alpha}$ line. This difficulty has been overcome with additional measurements of Compton-to-Rayleigh peak intensity ratio $N_{C} / N_{R}$ (Fig. 11) that has allowed decreasing the dispersion to 0.8 mass $\%$.

Let us assess the perspectives of application of the scattering method for analysis other light impurities in metals given below in Table. As it follows from Table, the concentration sensitivity of measurements increases noticeably with decreasing the

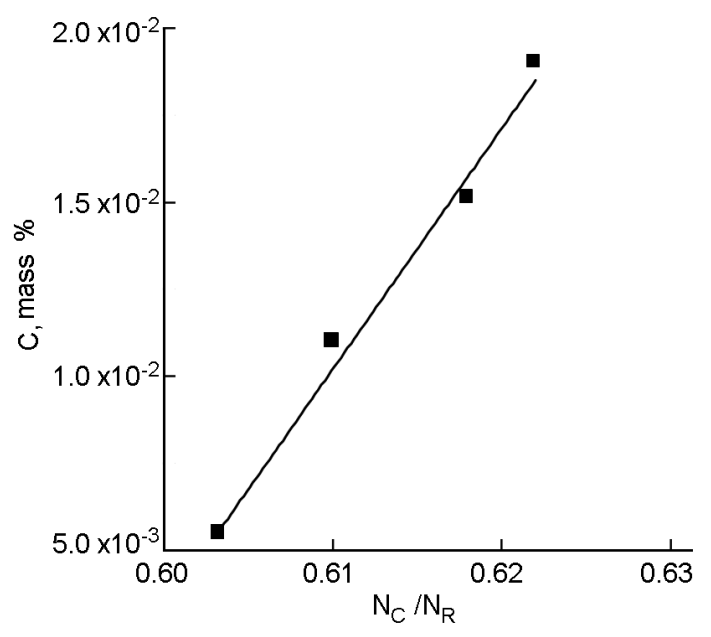

Fig. 12. Calibration plot for Compton-toRayleigh peak intensity ratio for $\mathrm{Ti}-\mathrm{H}$ system.

atomic number. The figures given in the Table show how the light element concentration measurement precision is higher than the measurement precision for the ratio of Compton-to-Rayleigh scattering peak integral intensities. Application of the optimized UPSF allows experimental achieving the measurement precision for the peak ratio about $0.1 \div 0.2 \%$ by relative value. According to the Table, that gives the possibility to determine, for example, variation of hydrogen content in niobium at the level $\frac{0.1 \%}{153.88 \% / \mathrm{mass} \%}=6.5 \cdot 10^{-4} \mathrm{mass} \%$.

Experimental tests on high sensitivity under determination of hydrogen content have been carried out with standard samples of the titanium hydrogen binary system (Fig. 12). The obtained values on the concentration sensitivity $170 \% /$ mass \% lated ones, although the cause has not been revealed yet. The measurements done for standard samples of titanium-hydrogen have proved the possibility to determine hydrogen in titanium beginning from $10^{-3}$ mass $\%$ for the time not more $5 \mathrm{~min}$. For $\mathrm{Fe}-\mathrm{C}$ system the value of the concentration sensitivity corresponded to the calculated one: $2.1 \%$ per 1 mass $\%$ that is quite enough for measuring the carbon with precision 0.05 mass $\%$.

Thus, the light impurities quantitative determination based on measuring the ratio of Compton-to-Rayleigh scattering peak intensities is found to be very promising due to significant penetration depth of hard radiation into the sample $(\sim 0.1 \div 1 \mathrm{~mm})$ and absence of artifacts related with the surface preparation. Sharp increase of $N_{C} / N_{R}$ ratio 
Table 1. Calculated values for concentration sensitivity $\frac{1}{N_{C} / N_{R}} \cdot \frac{\partial\left(N_{C} / N_{R}\right)}{\partial C}, \frac{\%}{\operatorname{mass} \%}$ under measuring

the light impurities in metals by the ratio of integral intensities of Compton and Rayleigh peaks.

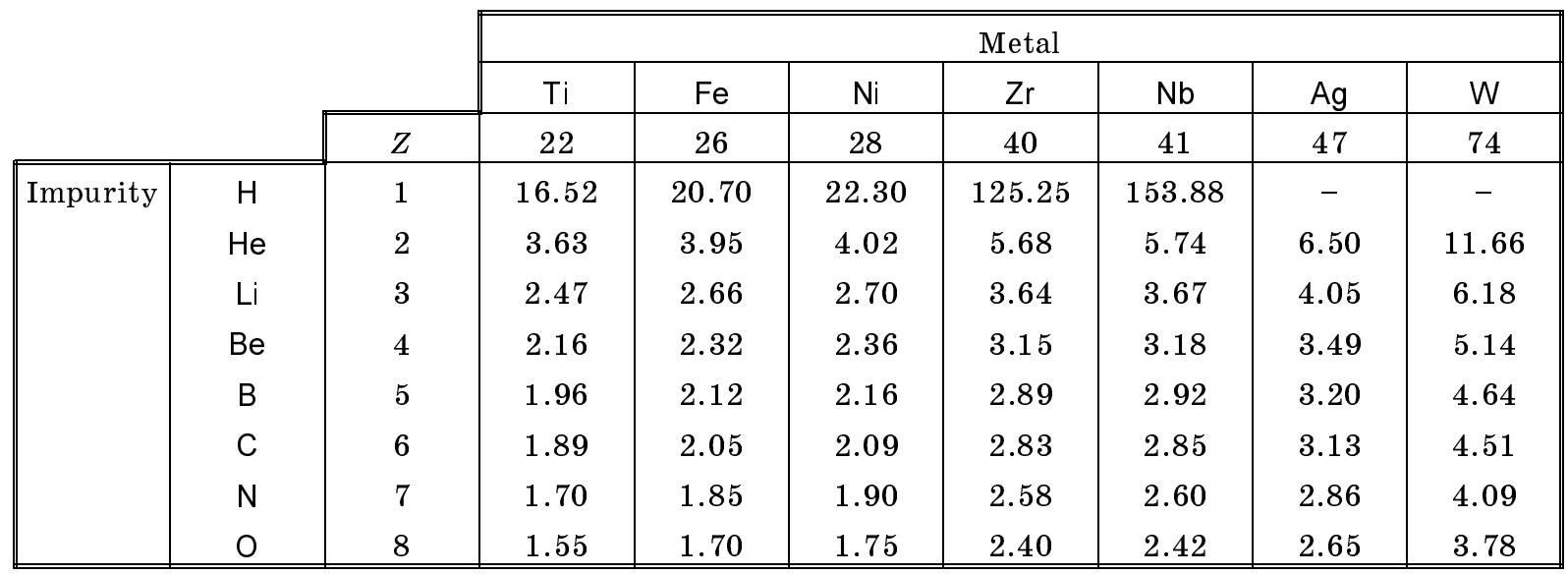

with decreasing atomic number provides the unique possibility to determine light elements of the Periodic System, including hydrogen, while the sensitivity being the higher, the lower is an element atomic number.

\section{Conclusions}

Further perspectives for X-ray analysis of materials are connected with preliminary formation of a selective initial spectrum directed onto the sample studied. Using such spectrum optimized by the criterion of the detection limit, it is possible to achieve the limit levels by sensitivity of X-ray fluorescent analysis about $0.01 \div 0.1 \mathrm{ppm}$, to widen up to hydrogen the range of measurable light elements at the expense of quantitative variations of the Compton-toRayleigh scattering peak intensity ratio, and to carry out quantitative X-ray phase analysis by diffraction reflections. In the present work, the optimization was carried out for the preliminary spectrum of a lowpower X-ray tube but some results by sensitivity was found to be record. We hope that application of the optimized units for formation of power beams of preliminary radiation (SM, undulators, wigglers, etc.) will allow to increase the analysis sensitivity up to ppb units with remaining all advantages of X-ray methods.

\section{References}

1. A.T.Ellis, Handbook of X-ray Spectrometry. Second Edition, Revised and Expended, ed. by E.Van Grieken, A.Markowicz, CRC Press (2001).
2. M.A.Blokhin, Methods for X-ray Spectral Investigations, Atomizdat, Moscow (1959) [in Russian].

3. R.V.Anisovich, Perspectives of Increasing Sensitivity of Fluorescent X-ray Spectral Analysis. Instruments and Methods of X-ray, Mashinostroenie, Leningrad (1980) [in Russian].

4. J.Heckel, Handbook of X-ray Spectrometry. Second Edition, Revised and Expended, ed. by E.Van Grieken, A.Markowicz, CRC Press (2001).

5. Y.Yoneda, T.Horiuchi, Rev.Sci.Instrum., 42, 1069 (1971).

6. I.F.Mikhailov, A.A.Baturin, A.I.Mikhailov, L.P.Fomina, Pribory $i$ Tekhnika Eksperimenta, No.4, 80 (2012).

7. V.P.Afonin, N.I.Komyak, V.P.Nikolayev, R.I.Plotnikov, X-ray Fluorescent Analysis, ed. by N.F.Losev, Nauka, Novosibirsk (1991) [in Russian].

8. K.V.Anisovich, Rentgenotekhnika, Handbook, vol.2, ed. by V.V.Kluyev, Mashinostroenie, Moscow (1980) [in Russian].

9. V.V.Davydov, Biochemical Constants of Human, Handbook, Kharkov (2005) [in Russian].

10. A.A.Shiryaev, in: Proc. of 7th International School of Earth Sci. ISES, Odessa 2-9 September 2011, Ukraine (2011), p. 23

11. A.V.Bakhtiyarov, I.V.Serikov, Coll:Instruments and Methods of X-ray Analysis, vol.19, Mashinostroenie, Leningrad (1977) [in Russian].

12. B.D.Kalinin, A.V.Rudnev, Analitika and Control, 15, 332 (2011).

13. A.H.Compton, Phys. Rev., 21, 483 (1923).

14. I.F.Mikhailov, O.V.Sobol, V.V.Varganov, L.P.Fomina, Functional Materials, 9, 651 (2002). 